\title{
Crack Growth Characteristic and Damage Evaluation under Creep-Fatigue Interactive Condition for W-Added High-Cr Steel ${ }^{* 1}$
}

\author{
Takashi Matsuzaki, Ryuji Sugiura*2, Yoshiko Nagumo*3 and A. Toshimitsu Yokobori, Jr. \\ Graduate School of Engineering, Tohoku University, Sendai 980-8579, Japan
}

\begin{abstract}
Crack growth characteristic under the conditions of high temperature creep and fatigue interaction is dominated by both of cyclic dependent mechanism due to fatigue and time dependent mechanism due to the time of load application (creep). For many cases with decrease in load frequency, this characteristic changes from the cyclic dependent mechanism to the time dependent mechanism through an unstable transition region induced by creep and fatigue competitive mechanisms. To understand the physical mechanism of the interactive effects of creep and fatigue, it is important to clarify the damage mechanisms around the crack. In the present study, the experiments of creep-fatigue crack growth tests and the quantitative analysis of damage by measuring Vickers hardness were conducted to understand the interactive effects of creep and fatigue on the crack growth characteristic. Additionally, by observing the material microstructure using EBSD, damage mechanisms were clarified. As a result, it was found that the creep effect contributes the expansion of damage region and the fatigue effect increases the density of damage within a given region. Interaction of these effects resulted in the occurrence of unstable transition region on the characteristic of creepfatigue life. [doi:10.2320/matertrans.M2013340]
\end{abstract}

(Received September 5, 2013; Accepted September 27, 2013; Published November 25, 2013)

Keywords: creep-fatigue crack, creep-fatigue damage, high-chromium steel, Vickers hardness, electron backscatter diffraction

\section{Introduction}

High-Cr ferritic heat resistant steels were developed for the use in components of high temperature instruments such as coal-fired fuel power plant. Now they have been widely used for the new generation power plants which are considering the reduction of environmental burden. The high-Cr steel has been reported to have excellent characteristics of creep strength and ductility due to the tempered martensitic lath structure. However, its degradation and damage formation behaviors under creep and creep-fatigue interactive conditions are not clarified quantitatively enough yet due to the complexity of material microstructure.

To solve these issues, methodological studies on damage evaluation under creep and creep-fatigue interactive conditions using EBSD method and measuring the Vickers hardness have been conducted. Some studies indicated that the dislocation density which is induced by martensitic lath structure decreases as the damage progresses. ${ }^{1-5)}$ Additionally, it is shown that the martensitic lath microstructure is thermally-stable and does not change under no applied load for Mod. 9\% Cr steel. ${ }^{4)}$ That is, the martensitic lath structure will change, depending on stress distribution resulting from the notched specimen with applied creep or creep-fatigue loadings. Moreover, it is reported that the crack initiation and growth behaviors of high-Cr steel are sensitive to the material microstructure, ${ }^{6}$ which lead to the scattering of crack initiation and growth lives.

Furthermore, the characteristics of creep crack growth life of $\mathrm{Cr}-\mathrm{Mo}-\mathrm{V}$ steel, 304 stainless steel and nickel-base superalloy under the creep-fatigue interactive conditions have been clarified by one of the present authors. ${ }^{7)}$ Yokobori et al. reported that crack growth characteristic under the

\footnotetext{
${ }^{* 1}$ This Paper was Originally Published in Japanese in J. Japan Inst. Metals 76 (2012) 624-633.

${ }^{* 2}$ Corresponding author, E-mail: sugiura@md.mech.tohoku.ac.jp

${ }^{*}$ Graduate Student, Tohoku University
}

conditions of high temperature creep and fatigue interaction is dominated by cyclic dependent mechanism due to fatigue and time dependent mechanism due to the time of load application (creep) and changes from the cyclic dependent to the time dependent mechanisms through an unstable transition region induced by creep and fatigue competitive mechanisms. ${ }^{7)}$ Additionally, to establish the law of fracture life under the creep-fatigue interactive conditions, the theoretical method considering the interactive effects of creep and fatigue have been proposed. However, its physical mechanism has not been clarified yet.

In the present study, the experiments of creep-fatigue crack growth tests and the quantitative analysis of damage by measuring Vickers hardness were conducted to understand the interactive effects of creep and fatigue on the crack growth characteristic. Additionally, by observing the material microstructure using EBSD, damage mechanisms were clarified.

\section{Materials}

The materials used are $\mathrm{W}$-added $9 \% \mathrm{Cr}$ steel and $\mathrm{W}$-added $12 \% \mathrm{Cr}$ steel. The chemical compositions of these materials are shown in Table $1 . \mathrm{W}$-added $9 \% \mathrm{Cr}$ steel is mainly used for the boiler component and $\mathrm{W}$-added $12 \% \mathrm{Cr}$ steel is used for the bolt, turbine blade and turbine rotor, which are expected to use under the temperatures of 593 and $650^{\circ} \mathrm{C}$, respectively. ${ }^{8)}$ IPF (Inverse pole figure) maps and pole figure maps of as-received $\mathrm{W}$-added $9-12 \% \mathrm{Cr}$ steels obtained by the EBSD observation are shown in Figs. 1 and 2, respectively. From the IPF maps shown in Fig. 1, the grain

Table 1 Chemical compositions of $\mathrm{W}$-added $9 \% \mathrm{Cr}$ and $12 \% \mathrm{Cr}$ steels in $\operatorname{mass} \%$.

\begin{tabular}{lccccccc}
\hline & $\mathrm{C}$ & $\mathrm{Cr}$ & $\mathrm{Mo}$ & $\mathrm{W}$ & $\mathrm{Nb}$ & $\mathrm{V}$ & $\mathrm{Co}$ \\
\hline W-added 9\% Cr steel & 0.101 & 8.96 & 0.48 & 1.97 & 0.065 & 0.201 & - \\
W-added 12\% Cr steel & 0.09 & 10.89 & 0.17 & 2.61 & 0.06 & 0.2 & 2.52 \\
\hline
\end{tabular}


(a)

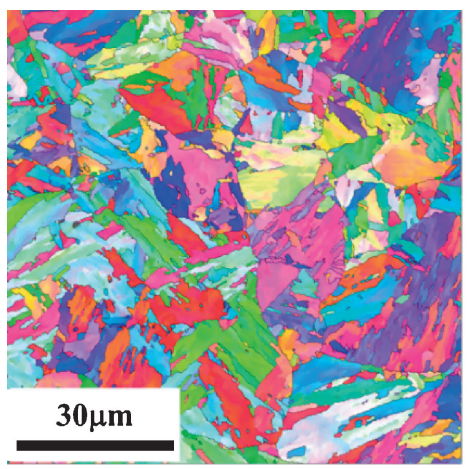

(b)

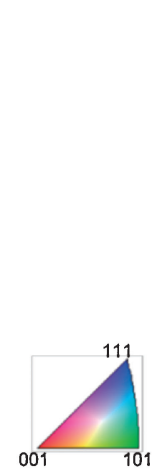

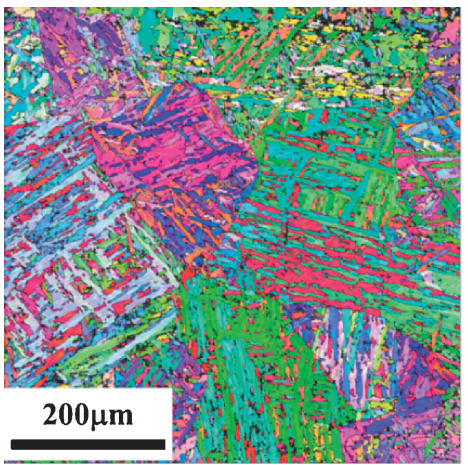

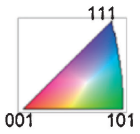

Fig. 1 IPF (Inverse pole figure) maps of W-added 9\% Cr and 12\% Cr steels; (a) W-added 9\% Cr steel, (b) W-added 12\% Cr steel.

(a)

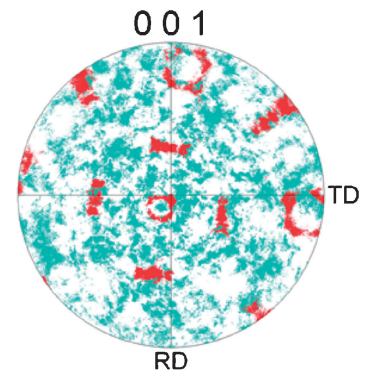

(b)

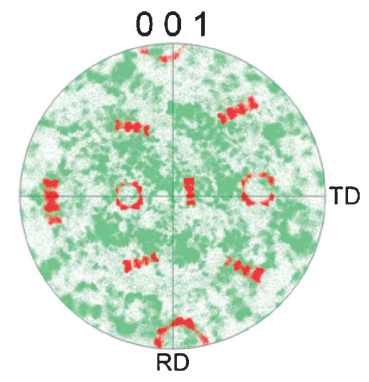

Fig. 2 Pole figure maps of $\mathrm{W}$-added $9 \% \mathrm{Cr}$ and $12 \%$ Cr steels; (a) W-added 9\% Cr steel, (b) W-added $12 \%$ Cr steel.

sizes of $\mathrm{W}$-added $9 \% \mathrm{Cr}$ steel and $\mathrm{W}$-added $12 \% \mathrm{Cr}$ steel are approximately 30 and $200 \mu \mathrm{m}$, respectively. The pole figure maps for the martensite phase shown in Figs. 2(a) and 2(b) represent the Kurdjumov-Sachs (K-S) orientation relationship which indicates that the $\mathrm{W}$-added $9-12 \% \mathrm{Cr}$ steels have martensitic lath microstructure.

\section{Experimental Procedure}

Crack growth tests under the creep-fatigue interactive conditions using $\mathrm{C}(\mathrm{T})$ specimens shown in Fig. 3 were performed on the basis of ASTM E1457-07 and E276010.9,10,11) The testing machine used was a lever arm high temperature creep-fatigue testing machine (Type RT-30) manufactured by TOSHIN KOGYO. The crack length and load line displacement were monitored during the tests. The crack length from the notch tip was measured by an electrical potential method using the Johnson-Schwalbes' equation as shown in eq. (1). ${ }^{12,13)}$

$a=\frac{2 W}{\pi} \times \cos ^{-1}\left\{\frac{\cosh \left(\pi y_{0} / 2 W\right)}{\cosh \frac{U}{U_{0}}\left[\cosh ^{-1}\left\{\frac{\cosh \left(\pi y_{0} / 2 W\right)}{\cos \left(\pi a_{0} / 2 W\right)}\right\}\right]}\right\}$

where $a$ is the length of the crack (mm), $a_{0}$ is the initial crack length $(\mathrm{mm}), y$ is the half distance between the output terminals $(\mathrm{mm}), U_{0}$ is the initial voltage $(\mu \mathrm{V}), U$ is the actual voltage of the specimen $(\mu \mathrm{V})$ and $W$ is the thickness of specimen $(\mathrm{mm})$. The test temperatures were kept at a specified temperature with the precision of $\pm 2^{\circ} \mathrm{C}$. The testing

Table 2 Crack growth tests condition.

\begin{tabular}{|c|c|c|c|c|c|}
\hline & $\begin{array}{c}\mathrm{T} \\
{\left[{ }^{\circ} \mathrm{C}\right]}\end{array}$ & $\begin{array}{c}\mathrm{K}_{\text {in }} \\
{\left[\mathrm{MPam}^{1 / 2}\right]}\end{array}$ & $\begin{array}{c}t_{\mathrm{R}} / t_{\mathrm{D}} \\
{[\mathrm{s}]}\end{array}$ & $\begin{array}{l}t_{\mathrm{H}} \\
{[\mathrm{s}]}\end{array}$ & $\begin{array}{c}t_{\mathrm{f}} \\
{[\mathrm{h}]}\end{array}$ \\
\hline \multirow{20}{*}{$\begin{array}{c}\text { W-added } \\
9 \% \text { Cr Steel }\end{array}$} & \multirow{8}{*}{600} & \multirow{20}{*}{35} & \multirow{7}{*}{35} & 0 & 105 \\
\hline & & & & 60 & 189.9 \\
\hline & & & & 600 & 484.3 \\
\hline & & & & 2500 & 753 \\
\hline & & & & \multirow{2}{*}{9940} & 861 \\
\hline & & & & & 460 \\
\hline & & & & 50000 & 1116 \\
\hline & & & \multicolumn{2}{|c|}{ Creep } & 850.5 \\
\hline & \multirow{6}{*}{615} & & \multirow{5}{*}{35} & 0 & 91 \\
\hline & & & & 60 & 139 \\
\hline & & & & 600 & 247 \\
\hline & & & & 2500 & 339.5 \\
\hline & & & & 9940 & 245 \\
\hline & & & \multicolumn{2}{|c|}{ Creep } & 417 \\
\hline & \multirow{6}{*}{630} & & \multirow{5}{*}{35} & 0 & 60 \\
\hline & & & & 60 & 68 \\
\hline & & & & 600 & 90 \\
\hline & & & & 9940 & 66 \\
\hline & & & & 50000 & 211 \\
\hline & & & \multicolumn{2}{|c|}{ Creep } & 215 \\
\hline \multirow{4}{*}{$\begin{array}{c}\text { W-added } \\
12 \% \text { Cr Steel }\end{array}$} & \multirow{4}{*}{650} & \multirow{4}{*}{35} & \multirow{3}{*}{35} & 0 & 92.5 \\
\hline & & & & 60 & 110 \\
\hline & & & & 600 & 113 \\
\hline & & & \multicolumn{2}{|c|}{ Creep } & 80 \\
\hline
\end{tabular}

conditions are shown in Table 2 and the stress waveform used in this experiment is shown in Fig. 4. Where, $T$ is the testing temperature $\left({ }^{\circ} \mathrm{C}\right), K_{\text {in }}$ is the initial stress intensity factor $\left(\mathrm{MPam}^{1 / 2}\right), t_{\mathrm{R}}$ is the stress raising time $(\mathrm{s}), t_{\mathrm{D}}$ is the stress decline time $(\mathrm{s}), t_{\mathrm{H}}$ is the stress holding time $(\mathrm{s}), t_{\mathrm{f}}$ is the crack growth life (h). As shown in Fig. 4, the crack growth tests under the creep-fatigue interactive conditions were conducted by changing the stress holding time $t_{\mathrm{H}}$ according to the ASTM standard. ${ }^{10)}$ 

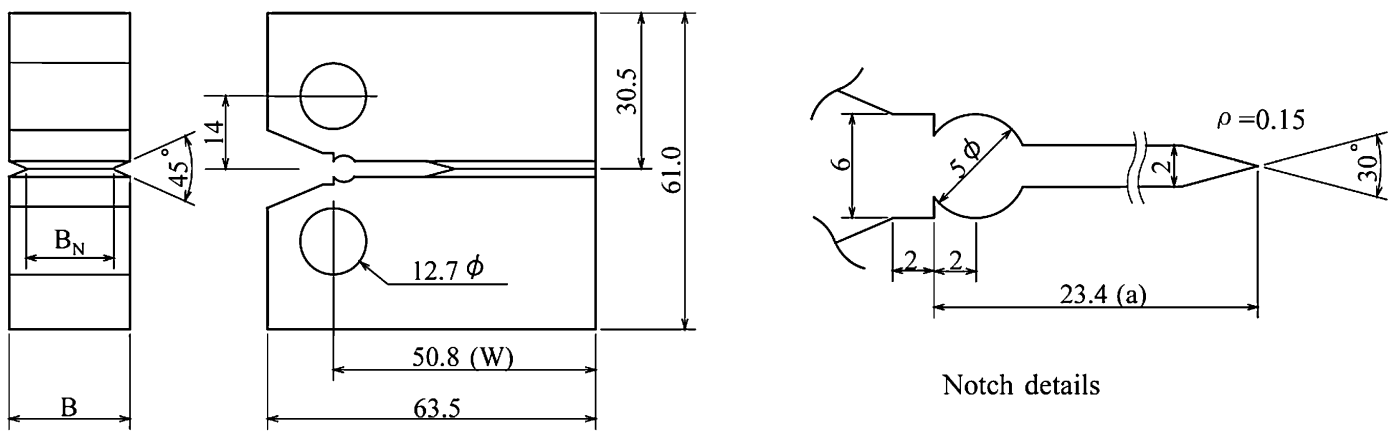

Notch details

$\mathrm{B}=25.4$

$\mathrm{B}_{\mathrm{N}}=0.75 \mathrm{~B}$

Fig. 3 Geometry and size of a $\mathrm{C}(\mathrm{T})$ specimen. (Unit: $\mathrm{mm}$ )

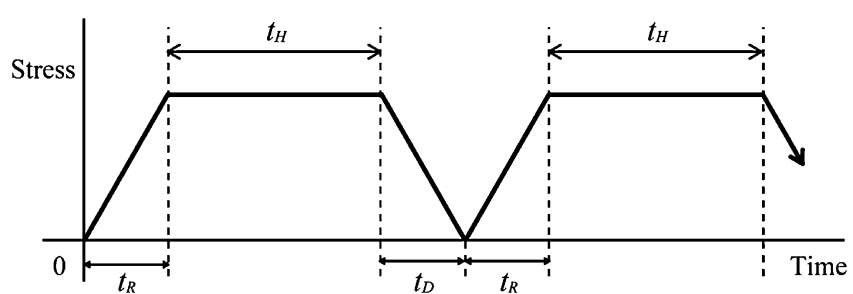

Fig. 4 Stress wave form based on ASTM Standard E2760-10.

The hardness measurement was conducted by microVickers hardness tester (SHIMADZU HMV-1). The loading force and the loading time were $98 \mathrm{mN}$ and $5 \mathrm{~s}$, respectively.

The orientation imaging microscopy (OIM) from TSL Inc. was used for fully-automated EBSD analysis to observe the crystallized microstructure such as the grain orientation distribution. The EBSD observations were conducted on a HITACHI S-4300 FE-SEM. Samples were polished to a mirror surface with $0.05 \mu \mathrm{m}$ colloidal silica solution to remove the worked layer before EBSD observation.

\section{Experimental Results}

\subsection{Characteristics of deformation and crack growth under creep-fatigue interactive conditions}

The characteristics of load line displacement and crack growth of $\mathrm{W}$-added $9-12 \% \mathrm{Cr}$ steel at temperatures of 600 and $650^{\circ} \mathrm{C}$, respectively, are shown in Figs. 5-8. The horizontal axis represents the normalized time $t / t_{\text {f }}$, where $t$ is the load application time and $t_{\mathrm{f}}$ is the fracture life for each specimen.

For the characteristic of load line displacement of $\mathrm{W}$-added 9\% $\mathrm{Cr}$ steel as shown in Fig. 5, the value of load line displacement increases with increase in stress holding time $t_{\mathrm{H}}$ ranging from 0 to $9940 \mathrm{~s}$ and takes a maximum value under the condition of $t_{\mathrm{H}}=9940 \mathrm{~s}$. When $t_{\mathrm{H}}$ is larger than $9940 \mathrm{~s}$, the value of load line displacement decreases and it saturates to that under creep condition. For the characteristic of crack growth of W-added 9\% Cr steel as shown in Fig. 6, the value of crack growth length decreases with increase in stress holding time $t_{\mathrm{H}}$ and it saturates to that under creep condition. Same tendency has been found for the characteristics of load line displacement and crack growth under the other testing temperature.

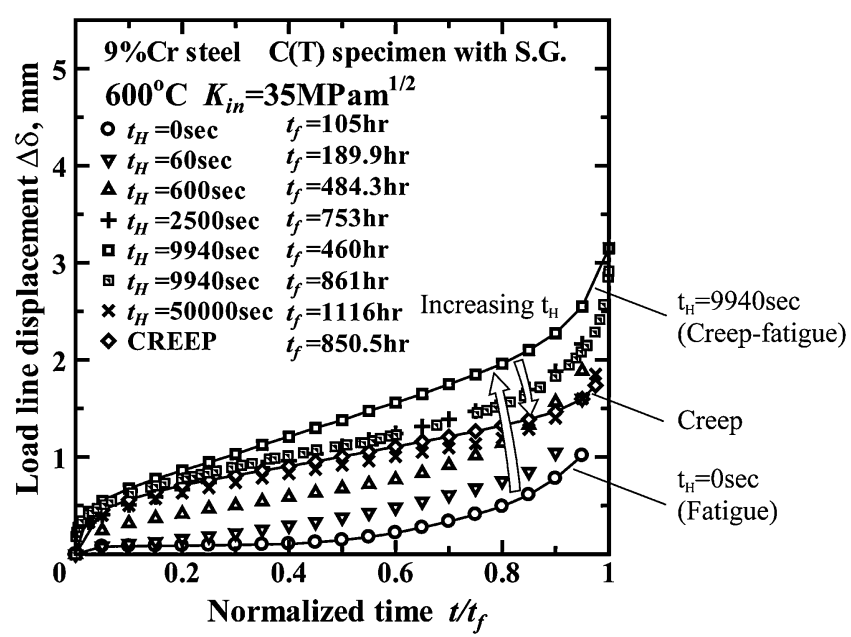

Fig. 5 Characteristic of load line displacement for $\mathrm{W}$-added $9 \% \mathrm{Cr}$ steel.

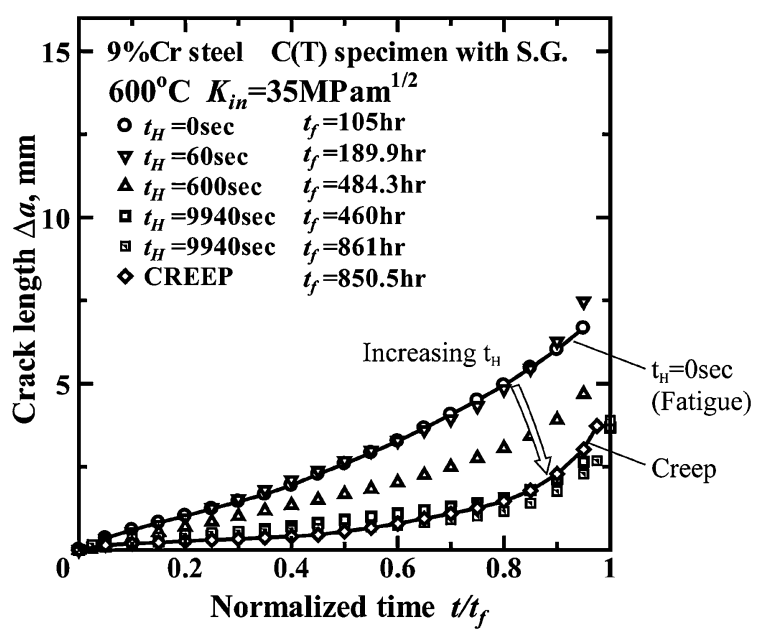

Fig. 6 Characteristic of crack growth for $\mathrm{W}$-added $9 \% \mathrm{Cr}$ steel.

On the other hand, for the characteristic of load line displacement of $\mathrm{W}$-added $12 \% \mathrm{Cr}$ steel as shown in Fig. 7 , the values of load line displacement under the creep-fatigue interactive conditions are much less than those of $\mathrm{W}$-added 9\% $\mathrm{Cr}$ steel, that is, creep deformation characteristic of $\mathrm{W}$ added $12 \% \mathrm{Cr}$ steel shows brittle manner as compared with that of $\mathrm{W}$-added $9 \% \mathrm{Cr}$ steel. The characteristic of load line displacement for $\mathrm{W}$-added $12 \% \mathrm{Cr}$ steel increases with the 


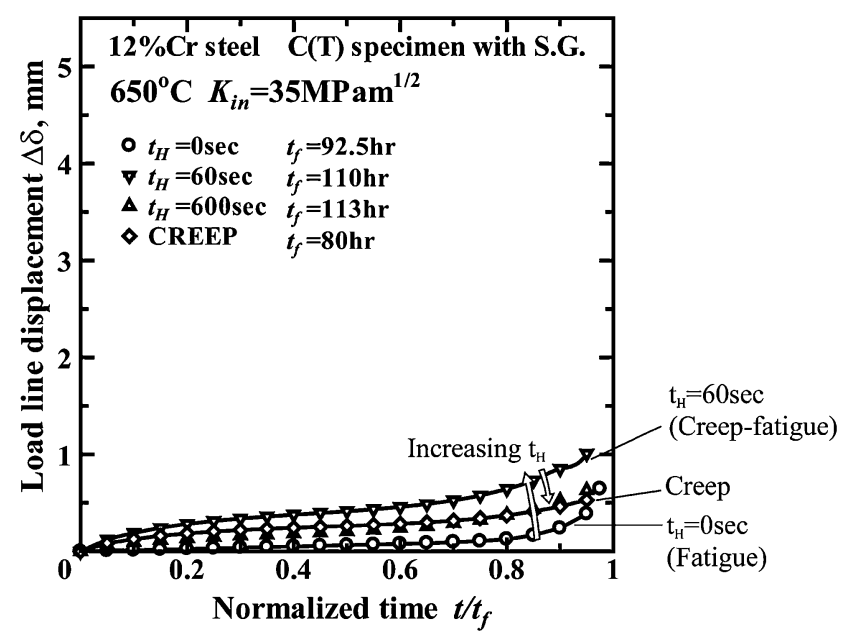

Fig. 7 Characteristic of load line displacement for $\mathrm{W}$-added $12 \% \mathrm{Cr}$ steel.

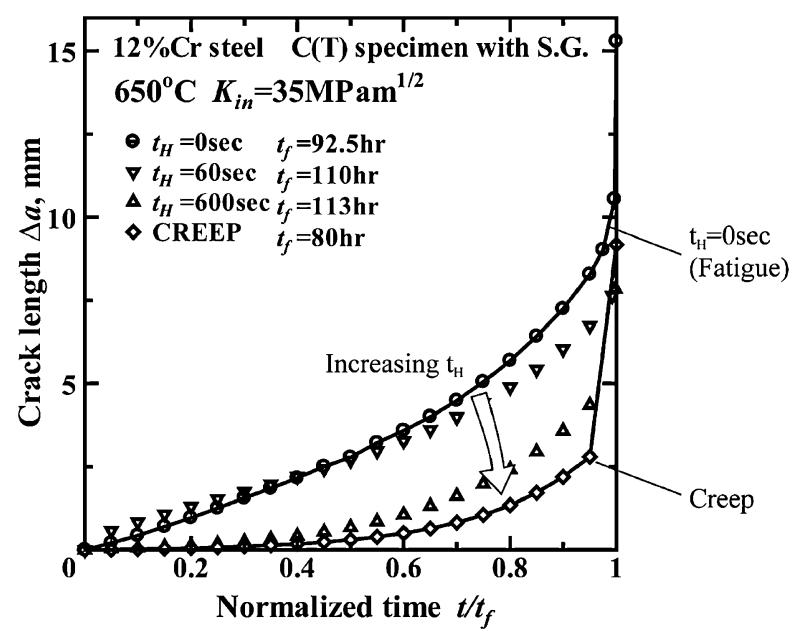

Fig. 8 Characteristic of crack growth for W-added $12 \% \mathrm{Cr}$ steel.

stress holding time increases and shows the maximum value at $t_{\mathrm{H}}=60 \mathrm{~s}$. When $t_{\mathrm{H}}$ is larger than $60 \mathrm{~s}$, the value of load line displacement decreases and saturates to that under creep condition. Additionally, the characteristics of crack growth length decrease with increase in stress holding time $t_{\mathrm{H}}$ and it saturates to that under creep condition as shown in Fig. 8.

\subsection{Characteristic of load frequency of crack growth life}

The characteristics of load frequency $f$ of crack growth life $t_{\mathrm{f}}$ for $\mathrm{W}$-added $9-12 \% \mathrm{Cr}$ steel are shown in Figs. 9 ${ }^{14,15)}$ and 10 . Where, the $x$-axis represents the frequency calculated by eq. (2) with variation in the stress holding time $t_{\mathrm{H}}$.

$$
f=\frac{1}{t_{\mathrm{R}}+t_{\mathrm{D}}+t_{\mathrm{H}}}
$$

As the experimental relationship between load frequency $f$ and crack growth life $t_{\mathrm{f}}$ shown in Figs. 9 and 10, the method for separate estimation of the cycle-dependent mechanism from the time-dependent mechanism is proposed for the characteristics of load frequency of crack growth life. ${ }^{7)}$ When the crack growth life $t_{\mathrm{f}}$ is dominated by the cycle-dependent mechanism, the relationship between $\log 1 / t_{\mathrm{f}}$ and $f$ is linear with a gradient of $45 \mathrm{deg}$. On the other hand, when the crack

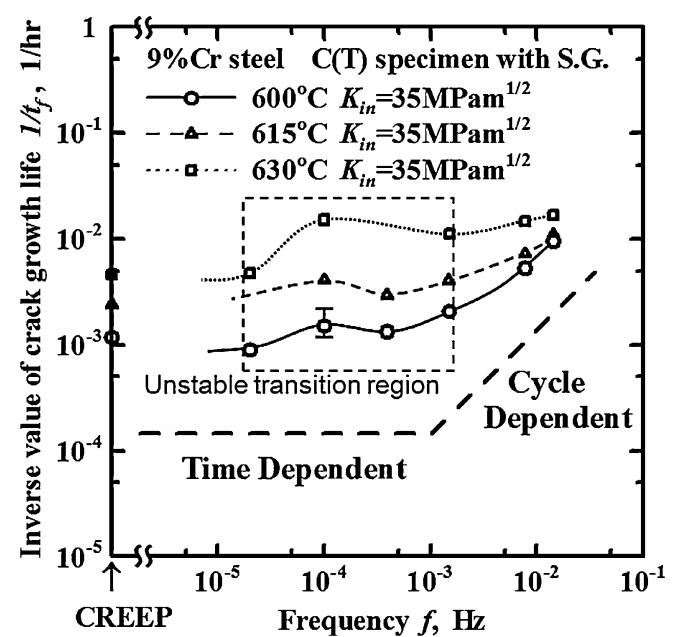

Fig. 9 Characteristic of crack growth life under creep-fatigue condition for W-added $9 \%$ Cr steel.

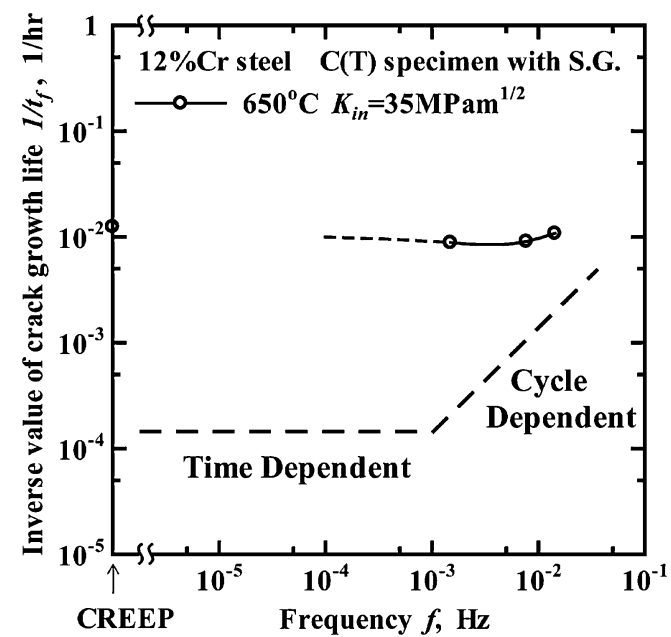

Fig. 10 Characteristic of crack growth life under creep-fatigue condition for $\mathrm{W}$-added $12 \% \mathrm{Cr}$ steel.

growth life $t_{\mathrm{f}}$ is dominated by the time-dependent mechanism, the relationship between $\log 1 / t_{\mathrm{f}}$ and $f$ is linear and parallel to the $\log f$ axis, i.e., there is a horizontal linear relationship between them. Therefore, from the experimental relationship between $1 / t_{\mathrm{f}}$ and $f$, the discrimination whether the crack growth life $t_{\mathrm{f}}$ is dominated by the cycle-dependent, time-dependent, or a competitive mechanism can be conducted. ${ }^{7)}$

In Fig. 9, the experimental results of $\mathrm{W}$-added $9 \% \mathrm{Cr}$ steel showed that the inverse value of crack growth life $1 / t_{\mathrm{f}}$ decreases approximately parallel to the life for the cycledependent mechanism with decrease in $f$ ranging from $10^{-2}$ to $10^{-3} \mathrm{~Hz}$. In the range of $10^{-3}$ to $10^{-5} \mathrm{~Hz}$, the characteristics of load frequency of crack growth life $t_{\mathrm{f}}$ showed an unstable equilibrium transition characteristic with an inflexion point. Furthermore, with increase in temperature, in the high load frequency range of $f>10^{-3} \mathrm{~Hz}$, the gradient of the linear relationship between $1 / t_{\mathrm{f}}$ and $f$ becomes small, which result in the appearance of time-dependent mechanism. From Fig. 10 the characteristic of load frequency of crack growth life $t_{\mathrm{f}}$ of $\mathrm{W}$-added $12 \% \mathrm{Cr}$ steel showed the time-dependent mechanism under all load frequency $f$. 
From these results mentioned above, the characteristic of load frequency of crack growth life showed multiple effects of time-dependent and cycle-dependent mechanisms as an unstable transition region. Additionally, this characteristic was found to be affected by testing temperature and the differences of materials. Yokobori et al. has been proposed the theoretical method considering the interactive effects of cycle-dependent and time-dependent mechanisms in order to establish the law of fracture life under the creep-fatigue interactive conditions. ${ }^{7}$ ) However, its physical mechanism has not been clarified yet.

To understand the physical mechanism of the interactive effects of creep and fatigue, it is important to clarify the damage mechanisms around the crack. In the next section, the quantitative analysis of damage by measuring Vickers hardness were conducted to understand the interactive effects of creep and fatigue on the crack growth characteristic.

\subsection{Micro-Vickers hardness measurement along the crack growth path}

By using micro-Vickers hardness test of HMV-1 manufactured by SHIMADZU, the micro-Vickers hardness was measured in the crack growth direction, which is $\mathrm{r}$ direction in Fig. 11, until $80 \%$ of the final crack length that is equal to the accelerating point of crack growth at regular intervals of $0.2 \mathrm{~mm}$. And the measurement was also conducted in the depth direction, which is d direction in Fig. 11, for $4 \mathrm{~mm}$ at regular intervals of $0.2 \mathrm{~mm}$. The micro-Vickers hardness $H$ was normalized by $H_{\mathrm{c}}$, which is the value of hardness measured far from the crack growth path, and classified in six grades with colors. The micro-Vickers hardness tests were conducted under the conditions of loading force and loading time, $98 \mathrm{mN}$ and $5 \mathrm{~s}$, respectively.

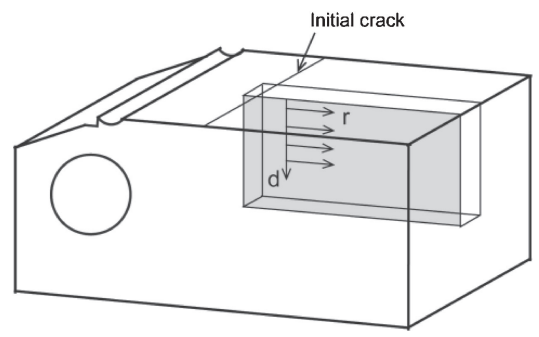

Fig. 11 Measurement and observational sites for tested specimen.
The normalized micro-Vickers hardness for $\mathrm{W}$-added $9 \%$ $\mathrm{Cr}$ steel tested under creep, fatigue $\left(t_{\mathrm{H}}=0 \mathrm{~s}\right)$, and creepfatigue interactive $\left(t_{\mathrm{H}}=9940 \mathrm{~s}\right)$ conditions at $600^{\circ} \mathrm{C}$ are shown in Figs. 12-14, respectively. The normalized microVickers hardness for $\mathrm{W}$-added $12 \% \mathrm{Cr}$ steel tested under creep, fatigue $\left(t_{\mathrm{H}}=0 \mathrm{~s}\right)$, and creep-fatigue interactive $\left(t_{\mathrm{H}}=600 \mathrm{~s}\right)$ conditions at $650^{\circ} \mathrm{C}$ are shown in Figs. $15-17$, respectively.

From Fig. 12, for W-added 9\% Cr steel tested under creep condition, the micro-Vickers hardness was degraded to the depth of $3.4 \mathrm{~mm}$ to the $\mathrm{d}$ direction, and the maximum degradation rate of hardness reaches 30\%. From Fig. 13, for $\mathrm{W}$-added $9 \% \mathrm{Cr}$ steel tested under fatigue condition $\left(t_{\mathrm{H}}=0 \mathrm{~s}\right)$, the micro-Vickers hardness was degraded to the depth of $1.2 \mathrm{~mm}$ to the direction, and the degradation rate of hardness was limited to 10-20\%. From Fig. 14, for $\mathrm{W}$-added 9\% $\mathrm{Cr}$ steel tested under creep-fatigue interactive condition $\left(t_{\mathrm{H}}=9940 \mathrm{~s}\right)$, the micro-Vickers hardness was degraded to the depth of $4.0 \mathrm{~mm}$ to the d direction, and the maximum degradation rate of hardness was $40 \%$.

From these results, the damage region and degree estimated from the degradation of hardness were most severe under creep-fatigue interactive condition.

From Fig. 15, for $\mathrm{W}$-added $12 \% \mathrm{Cr}$ steel tested under creep condition, the micro-Vickers hardness was degraded to

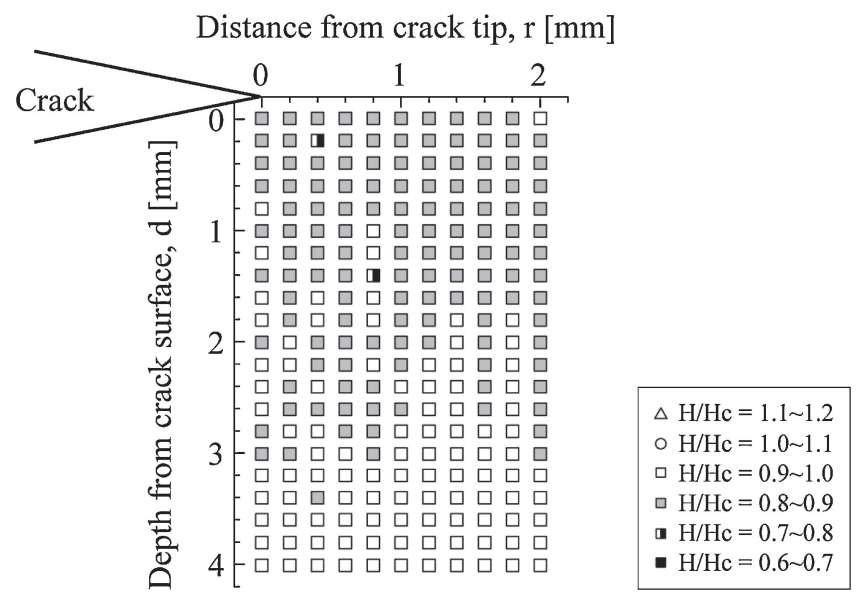

Fig. 12 Measurement result of Vickers hardness for W-added 9\% Cr steel under creep condition.

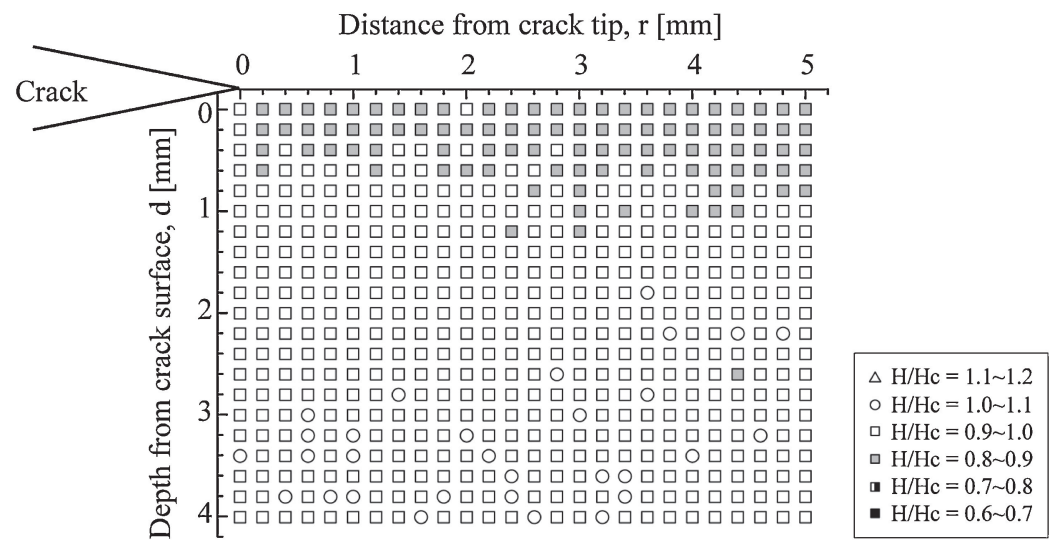

Fig. 13 Measurement result of Vickers hardness for $\mathrm{W}$-added $9 \% \mathrm{Cr}$ steel under fatigue condition. 


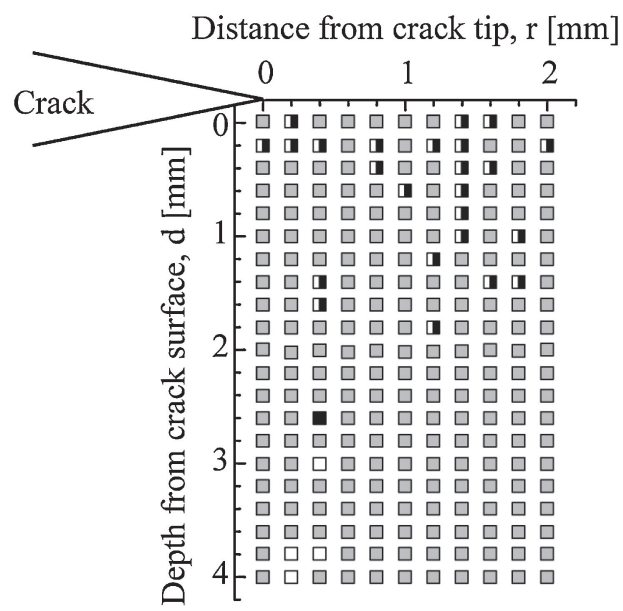

$\triangle \mathrm{H} / \mathrm{Hc}=1.1 \sim 1.2$
$\circ \mathrm{H} / \mathrm{Hc}=1.0 \sim 1.1$
$\square \mathrm{H} / \mathrm{Hc}=0.9 \sim 1.0$
$\square \mathrm{H} / \mathrm{Hc}=0.8 \sim 0.9$
a $\mathrm{H} / \mathrm{Hc}=0.7 \sim 0.8$
- $\mathrm{H} / \mathrm{Hc}=0.6 \sim 0.7$

Fig. 14 Measurement result of Vickers hardness for $\mathrm{W}$-added $9 \% \mathrm{Cr}$ steel under creep-fatigue condition. $\left(t_{\mathrm{H}}=9940 \mathrm{~s}\right)$

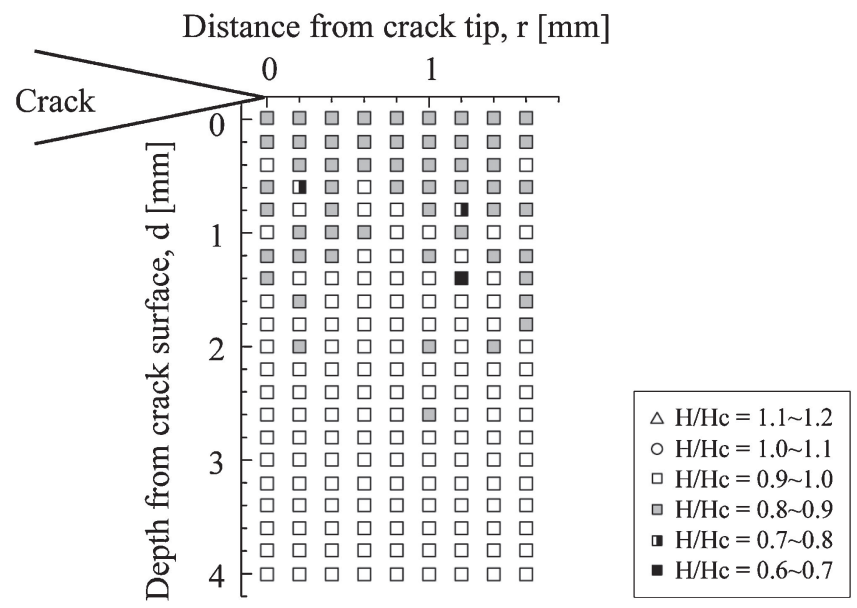

Fig. 15 Measurement result of Vickers hardness for $\mathrm{W}$-added $12 \% \mathrm{Cr}$ steel under creep condition.

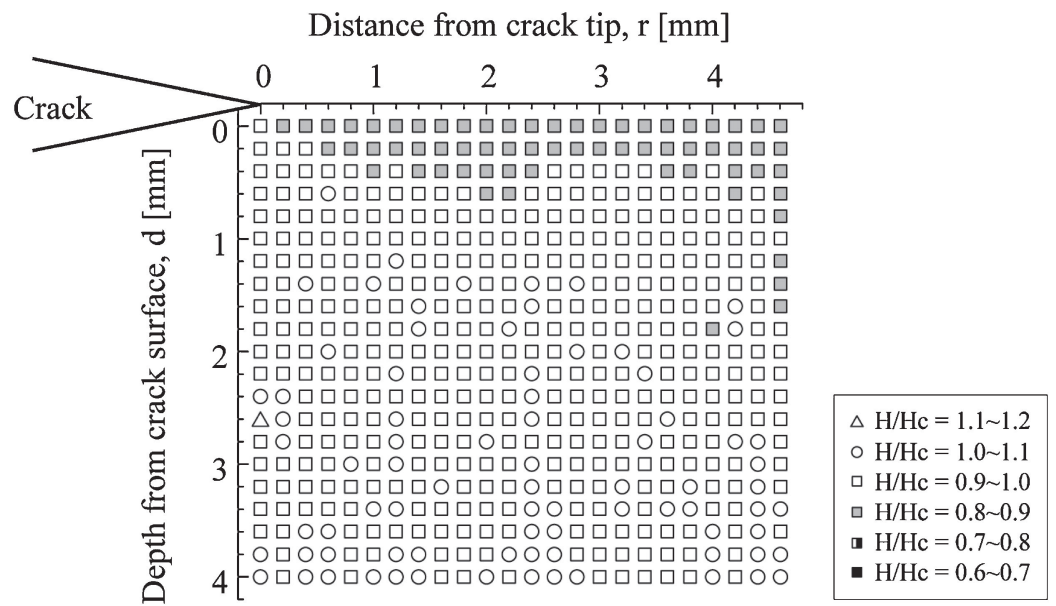

Fig. 16 Measurement result of Vickers hardness for $\mathrm{W}$-added $12 \% \mathrm{Cr}$ steel under fatigue condition.

the depth of $2.6 \mathrm{~mm}$ to the direction, and the maximum degradation rate of hardness reaches $40 \%$. From Fig. 16, for $\mathrm{W}$-added $12 \% \mathrm{Cr}$ steel tested under fatigue condition $\left(t_{\mathrm{H}}=0 \mathrm{~s}\right)$, the micro-Vickers hardness was degraded only to the depth of $1.8 \mathrm{~mm}$ to the direction, and the maximum degradation rate of hardness was limited to $20 \%$. From Fig. 17 , for $\mathrm{W}$-added $12 \% \mathrm{Cr}$ steel tested under creep-fatigue interactive condition $\left(t_{\mathrm{H}}=600 \mathrm{~s}\right)$, the micro-Vickers hardness was degraded up to the depth of $3.0 \mathrm{~mm}$ to the d direction, and the maximum degradation rate of hardness reaches $40 \%$. From these results, for $\mathrm{W}$-added $12 \% \mathrm{Cr}$ steel, it was shown that creep-fatigue damage formation behavior was similar to that under creep condition, different from the results for W-added $9 \%$ Cr steel.

From the results mentioned above, for $\mathrm{W}$-added $9 \% \mathrm{Cr}$ steel, the area and degree of damage under creep-fatigue interactive condition were notably larger and higher as compared with those of under the creep and fatigue conditions. Therefore, the reason why the unstable transition region in the characteristics of load frequency of crack growth life occurs under the creep-fatigue interactive condition may be due to the difference of damage formation behaviors as is mentioned above.

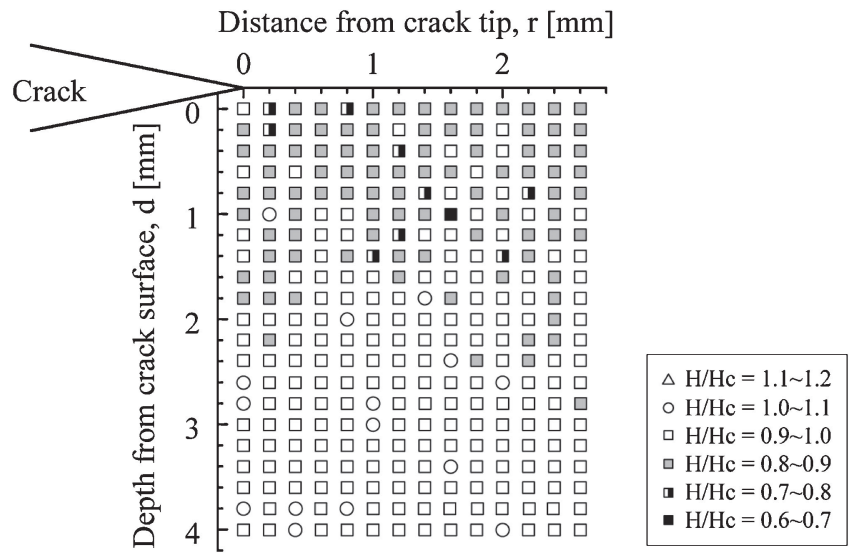

Fig. 17 Measurement result of Vickers hardness for $\mathrm{W}$-added $12 \% \mathrm{Cr}$ steel under creep-fatigue condition. $\left(t_{\mathrm{H}}=600 \mathrm{~s}\right)$

On the other hand, for $\mathrm{W}$-added $12 \% \mathrm{Cr}$ steel, the damage region under creep-fatigue interactive condition was similar to that of under creep condition. Therefore, it seems that the characteristics of load frequency of crack growth life $t_{\mathrm{f}}$ did not show unstable transition region and it was dominated by time-dependent mechanism. 
(a) $0.1 \mathrm{~mm}$

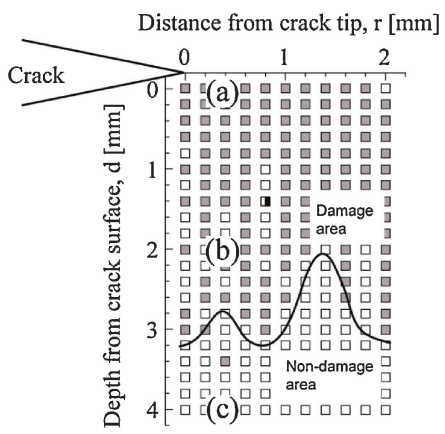

(b) $2 \mathrm{~mm}$
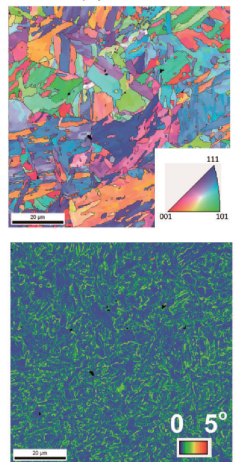

0.53 (0-2 deg.) (c) $4 \mathrm{~mm}$
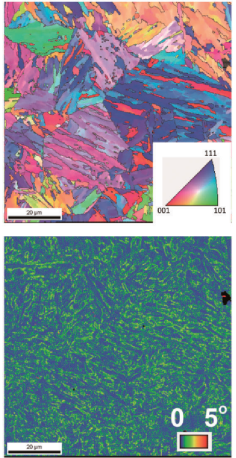

$0.58(0-2$ deg.)

Fig. 18 Inverse pole figure and Kernel average misorientation maps of W-added 9\% $\mathrm{Cr}$ under creep condition.

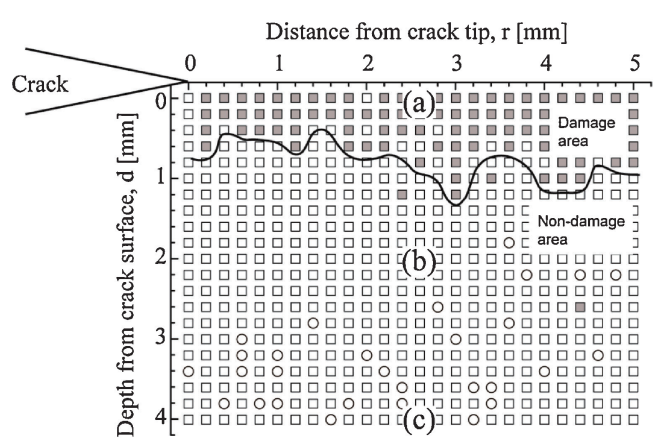

(a) $0.1 \mathrm{~mm}$

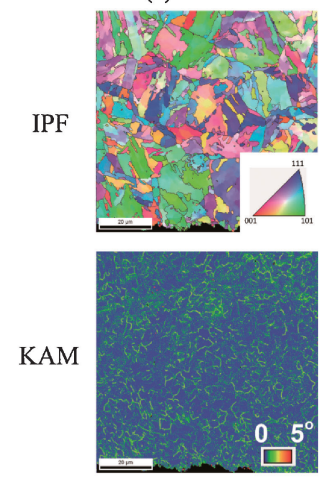

Ave. KAM : 0.45 (0-2 deg.) (b) $2 \mathrm{~mm}$
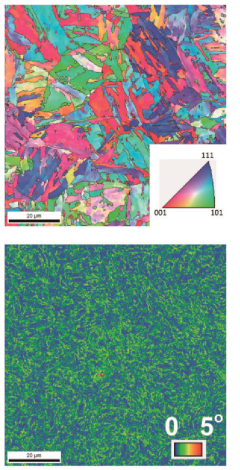

0.65 (0-2 deg.) (c) $4 \mathrm{~mm}$
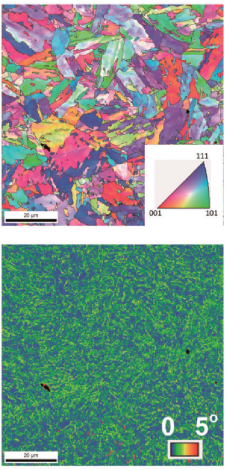

$0.68(0-2$ deg. $)$

Fig. 19 Inverse pole figure and Kernel average misorientation maps of W-added 9\% $\mathrm{Cr}$ steel under fatigue condition.

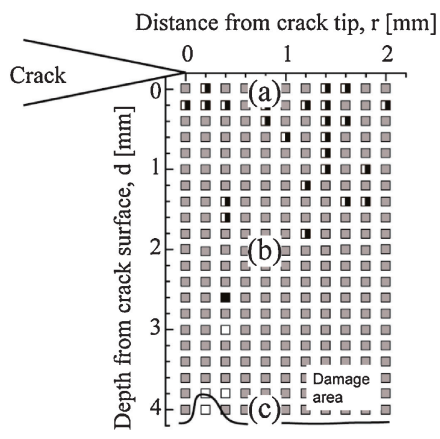

(a) $0.1 \mathrm{~mm}$
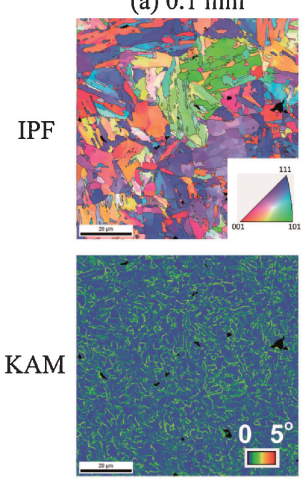

Ave. KAM : $0.46(0-2$ deg. $)$ (b) $2 \mathrm{~mm}$
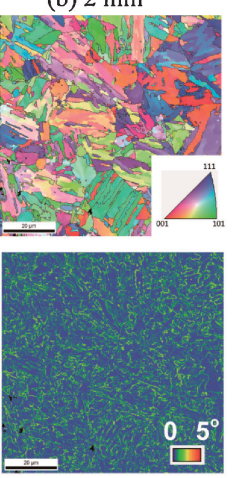

$0.47(0-2$ deg. $)$ (c) $4 \mathrm{~mm}$
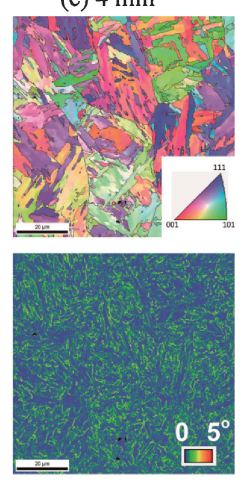

$0.52(0-2$ deg. $)$

Fig. 20 Inverse pole figure and Kernel average misorientation maps of $\mathrm{W}$-added $9 \% \mathrm{Cr}$ steel under creep-fatigue condition. $\left(t_{\mathrm{H}}=9940 \mathrm{~s}\right)$

In the next section, to clarify the contributing factor of damage formation, microstructural observation by using EBSD was conducted.

\subsection{Microstructural observation of damage region using EBSD method}

The EBSD observation was conducted on a HITACHI S-4300 FE-SEM. The OIM from TSL Inc. was used for fullyautomated EBSD analysis to observe the microstructure such as the grain orientation distribution. Samples were polished to a mirror surface with $0.05 \mu \mathrm{m}$ colloidal silica solution to remove the worked layer before EBSD observation. The observational points were in the position which corresponds to $t / t_{\mathrm{f}}=0.5$ in the $\mathrm{r}$ direction shown in the Figs. 6 and 8 . At this position in the $r$ direction, the measurement points were determined directly below the crack surface $(0.1 \mathrm{~mm})$, at $2 \mathrm{~mm}$, and at $4 \mathrm{~mm}$ in the d direction. The EBSD observation was conducted with $0.2 \mu \mathrm{m}$ step size in the $87 \mu \mathrm{m}$ square area for each measurement point. The inverse pole figure (IPF) maps and the kernel average misorientation (KAM) maps are shown in Figs. 18-23. The KAM value represents the difference of crystal orientation which is calculated by the average misorientation between a point and its neighbors. 

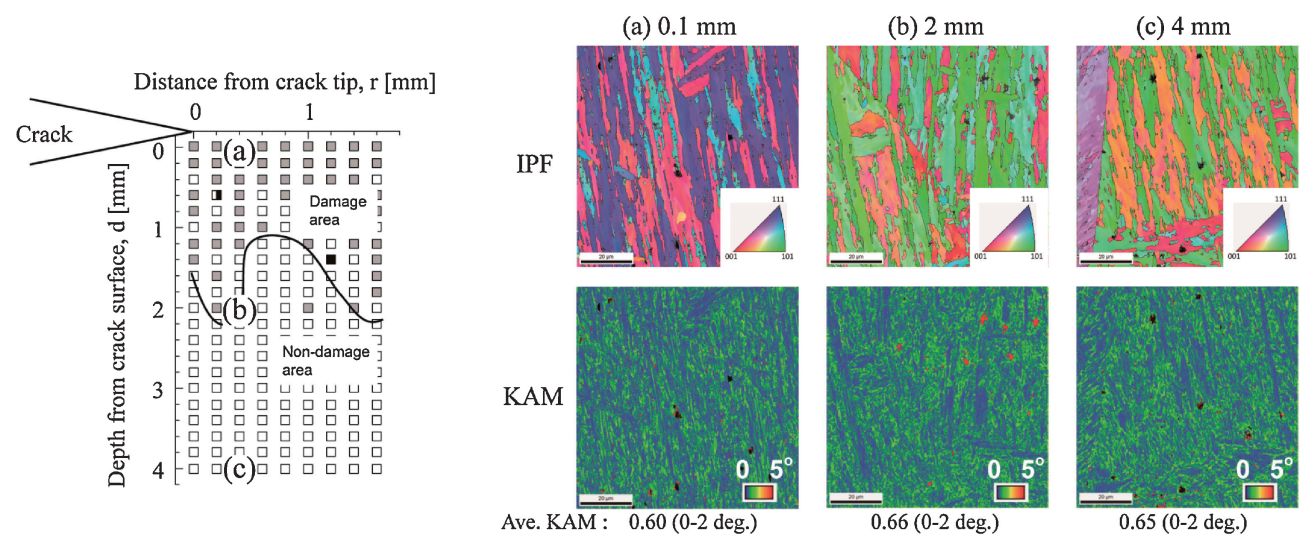

Fig. 21 Inverse pole figure and Kernel average misorientation maps of W-added $12 \% \mathrm{Cr}$ under creep condition.
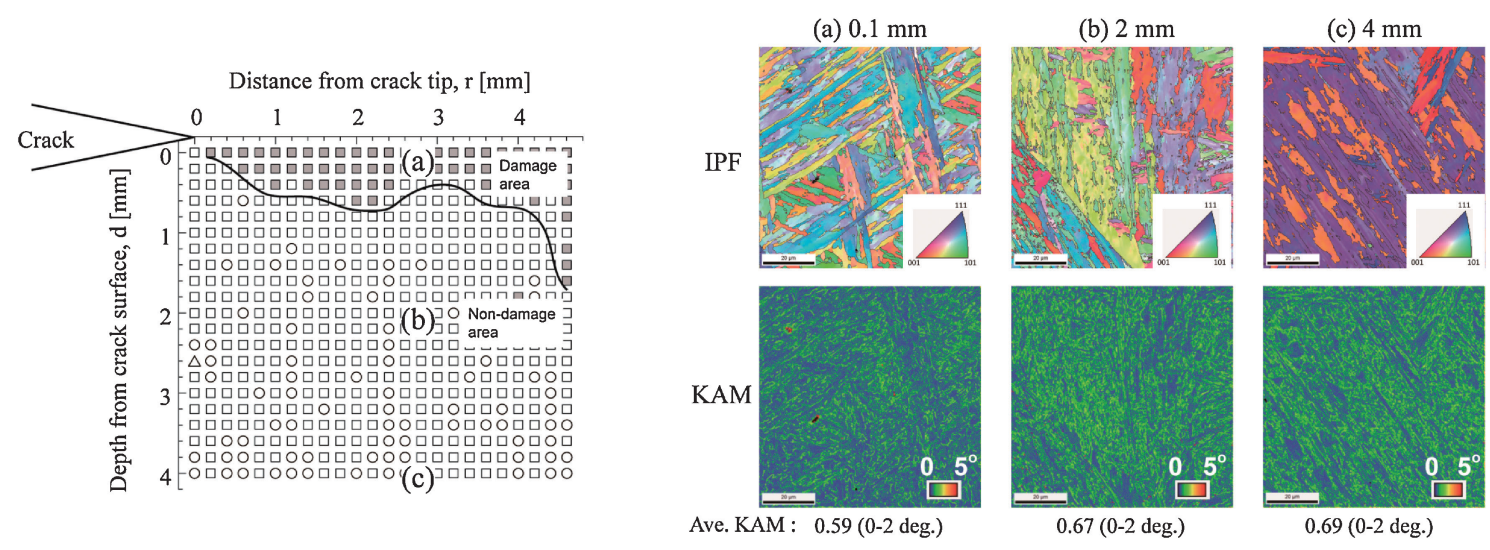

Fig. 22 Inverse pole figure and Kernel average misorientation maps of $\mathrm{W}$-added $12 \% \mathrm{Cr}$ steel under fatigue condition.
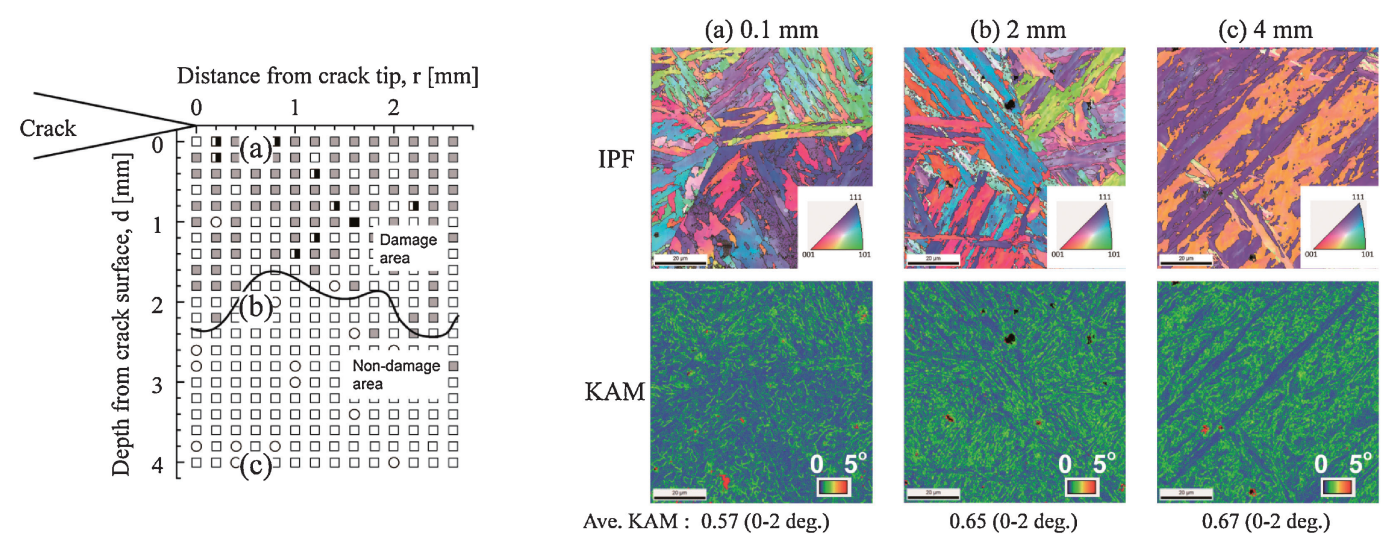

Fig. 23 Inverse pole figure and Kernel average misorientation maps of $\mathrm{W}$-added $12 \% \mathrm{Cr}$ steel under creep-fatigue condition. $\left(t_{\mathrm{H}}=600 \mathrm{~s}\right)$

As shown in Figs. 18-20, for W-added 9\% Cr steel, the distribution of KAM value in the damage region which is revealed from micro-Vickers hardness is different from that in the other region (undamaged region). Additionally, the average KAM value for an EBSD observational area is lowest in the damage region.

From the IPF and KAM maps shown in Figs. 21-23, for $\mathrm{W}$-added $12 \% \mathrm{Cr}$ steel, the similar results were obtained with $\mathrm{W}$-added $9 \% \mathrm{Cr}$ steel. To clarify the difference of KAM value in damage region and undamaged region, the frequency distributions of the KAM value for the EBSD observational areas in Figs. 18-23 are shown in Figs. 24 and 25.
Figures 24(a), 24(b) and 24(c) show the frequency distributions of the KAM value for $\mathrm{W}$-added $9 \% \mathrm{Cr}$ steel at the depths of $0.1,2.0$ and $4.0 \mathrm{~mm}$ from crack surface. In a similar way, the frequency distributions of the KAM value for Wadded $12 \% \mathrm{Cr}$ steel are shown in Figs. 25(a), 25(b) and 25(c).

For $\mathrm{W}$-added $9 \% \mathrm{Cr}$ steel, the distribution of KAM value at the depth of $0.1 \mathrm{~mm}$ from the crack surface was not different under various testing conditions as shown in Fig. 24(a). From these results, the damage region is formed under any testing conditions at the depth of $0.1 \mathrm{~mm}$ from the crack surface. On the other hand, from Fig. 24(b), at the depth of $2.0 \mathrm{~mm}$ from the crack surface, the distribution 

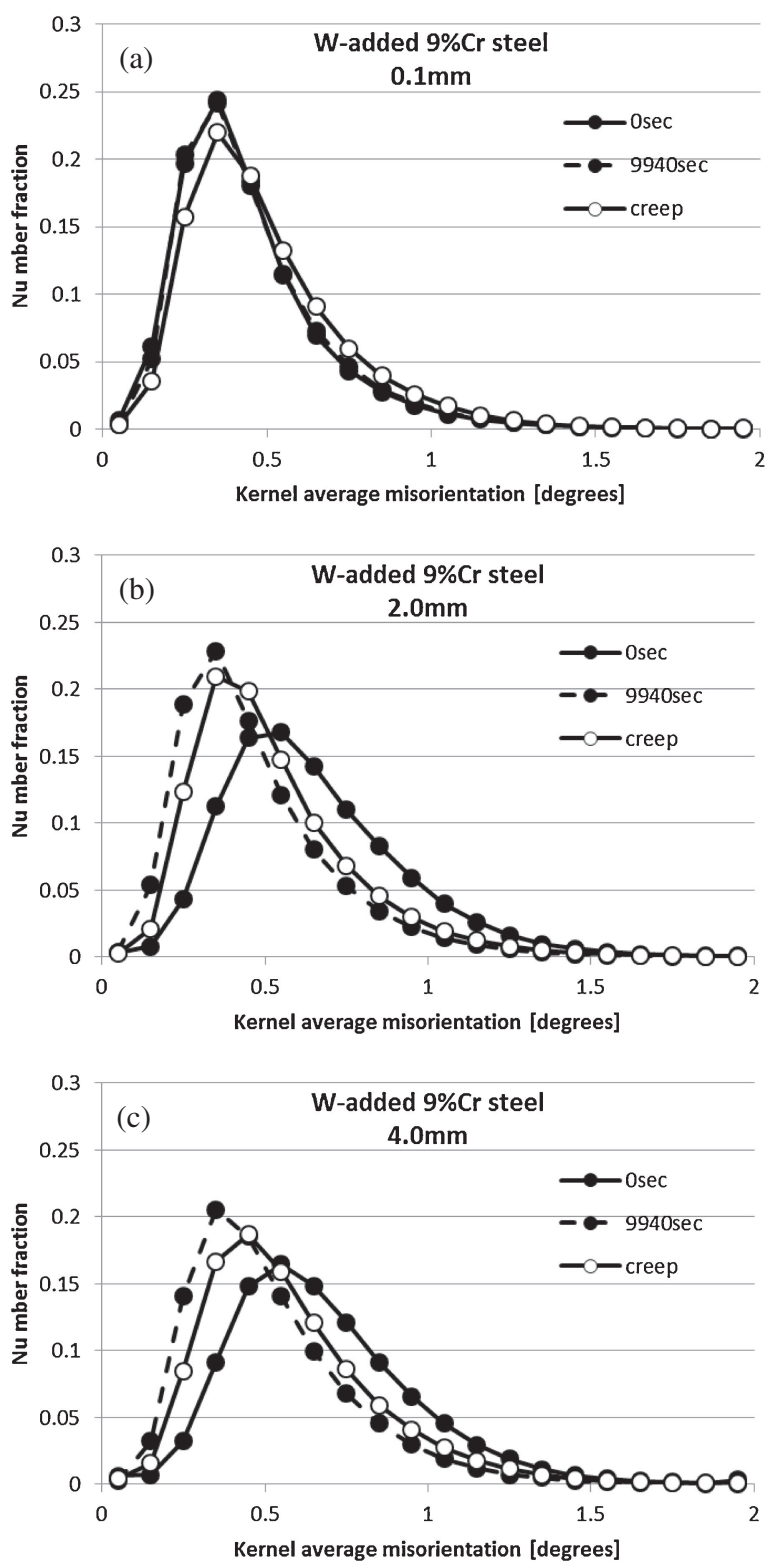

Fig. 24 Number fraction of KAM in damage region of $\mathrm{W}$-added $9 \% \mathrm{Cr}$ steel; (a) $0.1 \mathrm{~mm}$, (b) $2.0 \mathrm{~mm}$, (c) $4.0 \mathrm{~mm}$.

of the KAM values under fatigue condition was different from those of under creep and creep-fatigue interactive $\left(t_{\mathrm{H}}=9940 \mathrm{~s}\right)$ conditions. Furthermore, the peak of KAM value moved to the higher side of the misorientation angle under fatigue condition and lower side of the misorientation angle under creep and creep-fatigue interactive conditions. From these results, the damage formation was not occurred at this depth under fatigue condition; therefore, the peak of KAM value moved to the higher side of the misorientation angle due to the remaining high dislocation density of martensite lath structure. ${ }^{3,16)}$ On the other hand, under creep and creep-fatigue conditions, the peak of KAM value moved to the lower side of the misorientation angle due to the recovery of martensite lath structure. ${ }^{3,16)}$

Additionally, from Fig. 24(c), at the depth of $4.0 \mathrm{~mm}$ from the crack surface, the peak of KAM value under creep condition moved to the higher side of the misorientation angle corresponding to the undamaged region.
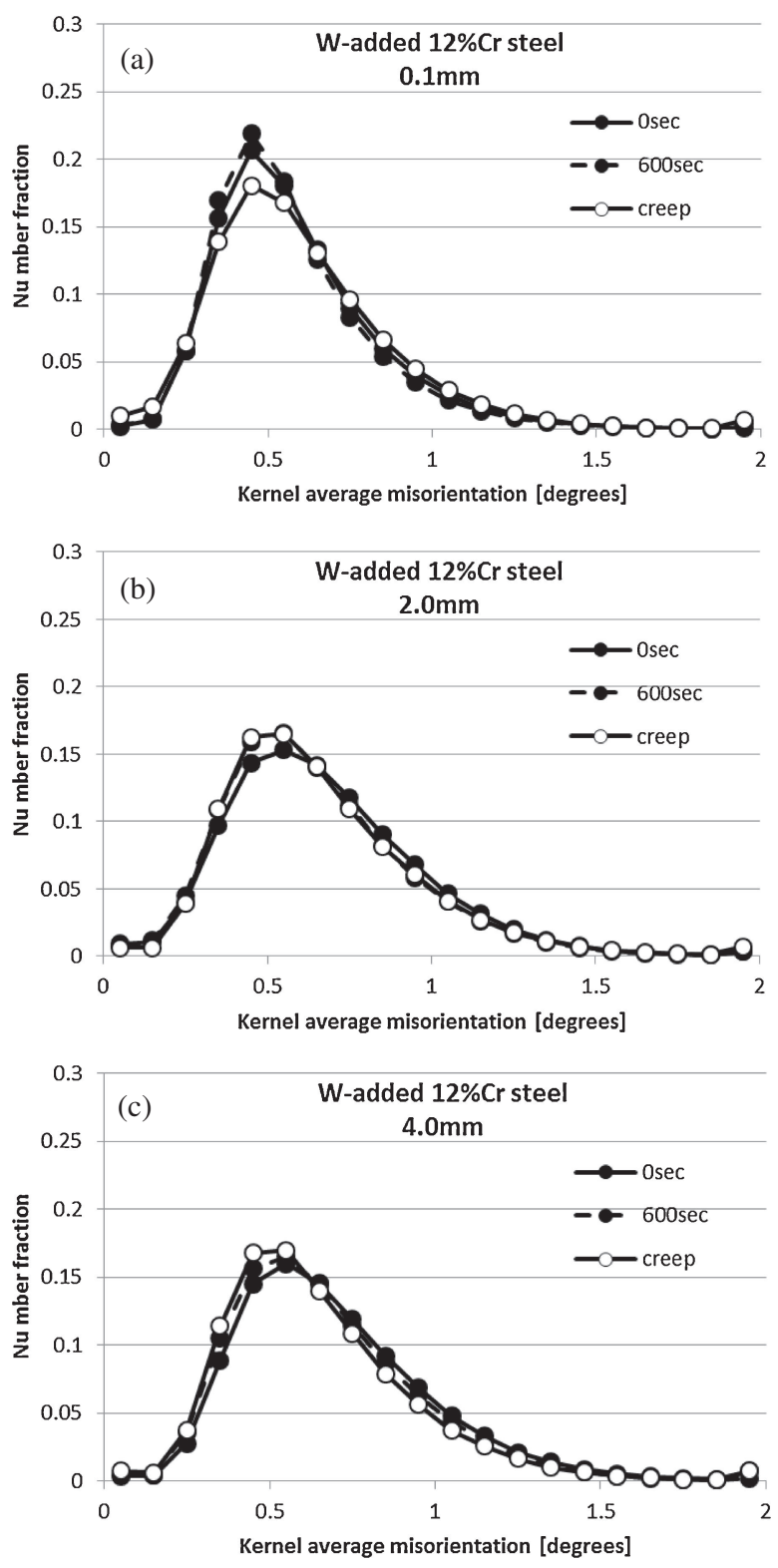

Fig. 25 Number fraction of KAM in damage region of $\mathrm{W}$-added $12 \% \mathrm{Cr}$ steel; (a) $0.1 \mathrm{~mm}$, (b) $2.0 \mathrm{~mm}$, (c) $4.0 \mathrm{~mm}$.

As shown in Figs. 25(a), (b) and (c), for W-added 12\% Cr steel, the distribution of the KAM values was almost similar characteristics under any condition at each depth. The difference of the distribution of damage region under creep, fatigue, and creep-fatigue interactive conditions for $\mathrm{W}$-added $12 \% \mathrm{Cr}$ steel, which is estimated by the micro-Vickers hardness, does not affect the difference in KAM value. Therefore, this is the reason why the characteristic of crack growth life for $\mathrm{W}$-added $12 \% \mathrm{Cr}$ steel does not show the effect of creep-fatigue interaction.

\section{Conclusions}

For $\mathrm{W}$-added $9 \% \mathrm{Cr}$ steel, it is clarified that high damage region is formed widely under creep-fatigue interactive condition due to the interactive effect of creep which damage formation is widely occurred and fatigue which damage formation is high localized along the crack growth path. The 
frequency range which causes the interactive effect of creep and fatigue damage is correlated to the frequency range of unstable transition region of the characteristic of crack growth life. For $\mathrm{W}$-added $12 \% \mathrm{Cr}$ steel, the characteristic of crack growth life was found to be mainly dominated by time dependent mechanism even under creep and fatigue condition.

\section{REFERENCES}

1) J. Pešička, R. Kužel, A. Dronhofer and G. Eggeler: Acta Mater. 51 (2003) 4847-4862.

2) M. Kamaya, A. J. Wilkinson and J. M. Titchmarsh: INSS J. 11 (2004) $161-172$.

3) K. Kimura, K. Fujiyama, R. Ishii and K. Saito: Trans. Japan Soc. Mech. Eng. Ser. A 66 (2000) 158-164.

4) K. Sawada, K. Maruyama, R. Komine and Y. Nagae: Tetsu-to-Hagane 83 (1997) 54-59.

5) T. Ohtani, F. Yin and Y. Kamada: J. Soc. Mater. Sci. Japan 58 (2009)
136-142.

6) R. Sugiura, A. T. Yokobori, Jr., S. Takamori, M. Tabuchi, A. Fuji, M. Yoda, K. Kobayashi and T. Yokobori: Mater. Trans. 48 (2007) 29282936.

7) A. T. Yokobori, Jr., K. Akaishi, R. Sugiura and D. Kobayashi: Strength, Fracture and Complexity An Int. J. 2 (2004) 35-45.

8) T. Fujita: The Thermal and Nuclear Power 42 (1991) 1485-1495.

9) ASTM E1457-07, Standard test method of measurement of creep crack growth rates in metals, Annual Book of ASTM Standards, (2007).

10) ASTM E2760-10, Standard test method for creep-fatigue crack growth testing.

11) T. Yokobori, T. Iwadate, S. Konosu, M. Tabuchi, A. Fuji and A. T. Yokobori, Jr.: Strength of Materials and Fractology, 129, (Committee of JSPS, Sasaki Press Japan, 1999) p. 291.

12) H. H. Johnson: Mater. Res. Stand. 5 (1965) 442-445.

13) K. H. Schwalbe and D. Hellman: J. Test. Eval. 9 (1981) 218-220.

14) A. T. Yokobori, Jr., R. Sugiura, D. Yoshino, M. Tabuchi and Y. Hasegawa: Proc. ASME PVP07 CREEP8, (2007) CD-ROM.

15) A. T. Yokobori, Jr., R. Sugiura, S. Kimoto, D. Yoshino and T. Matsuzaki: Proc. ASME PVP09, (2009) CD-ROM.

16) H. Nakashima: Tetsu-to-Hagane 90 (2004) 23-28. 